\title{
Effects of enoxaparin and unfractionated heparin in prophylactic and therapeutic doses on the fertility of female Wistar rats ${ }^{1}$
}

\author{
Ernesto Antonio Figueiró-FilhoI, Ricardo Dutra Aydos ${ }^{\mathrm{II}}$, Flávio Renato de Almeida Senefonte ${ }^{\mathrm{III}}$, Cristiane Munaretto Ferreira ${ }^{\mathrm{III}}$, \\ Érica Freire de Vasconcelos Pereira ${ }^{\mathrm{III}}$, Vanessa Marcon de Oliveira ${ }^{\mathrm{IV}}$, Giovanna Pádoa de Menezes ${ }^{\mathrm{V}}$, Marco Antonio Costa Bósio ${ }^{\mathrm{V}}$
}

DOI: http://dx.doi.org/10.1590/S0102-86502014000700001

${ }^{I} \mathrm{PhD}$, Associate Professor, Director Faculty of Medicine, Federal University of Mato Grosso do Sul (FAMED/UFMS), Campo Grande-MS, Brazil. Conception, design, intellectual and scientific content of the study, supervised all phases of the study, critical revision, final approval.

IIPhD, Associate Professor, Coordinator, Postgraduate Program in Health and Development of Midwestern Region, FAMED/UFMS, Campo GrandeMS, Brazil. Intellectual and scientific content of the study, critical revision, final approval.

IIIFellow Master degree, Postgraduate Program in Health and Development of Midwestern Region, FAMED/UFMS, Campo Grande-MS, Brazil. Technical procedures, acquisition and interpretation of data, statistical analysis, manuscript writing, critical revision.

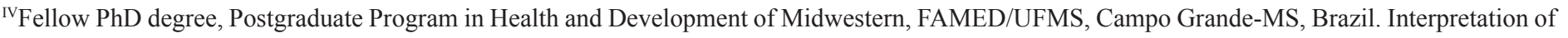
data, statistical analysis, manuscript writing, critical revision.

${ }^{v}$ Graduate student, FAMED/UFMS, Campo Grande-MS, Brazil. Technical procedures, acquisition and interpretation of data.

\section{ABSTRACT}

PURPOSE: To evaluate the effects of exposure of enoxaparin and unfractionated heparin (UFH) in prophylactic and therapeutic doses on the fertility rates of pregnant healthy Wistar rats.

METHODS: Enoxaparin and UFH were administered in prophylactic doses $1 \mathrm{mg} / \mathrm{Kg} /$ day $72 \mathrm{UI} / \mathrm{Kg} /$ day, and in therapeutic doses at $2 \mathrm{mg} / \mathrm{kg} / \mathrm{day} 400 \mathrm{UI} / \mathrm{Kg} / \mathrm{day}$. The rats were divided into five groups. The number of live and dead foetuses was quantified. The uterine horns were dissected and the presence of early and late reabsorptions (abortions) was determined. A $p<0.05$ was considered statistically significant.

RESULTS: We did not observe statistically significant differences between groups when comparing the average weight of the foetuses and placentas, rate of female VS males, rates of pre-implantation loss (RPL), rates of efficiency implantation (REI), rates of postimplantation loss (RPIL) and rates of foetal viability (RFV).

CONCLUSIONS: There was no significant effect on fertility with the use of anticoagulant drugs in pregnant healthy Wistar rats. Key words: Heparin. Enoxaparin. Fertility. Pregnancy. Rats. 


\section{Introduction}

Thromboembolic disease is the leading cause of maternal mortality during pregnancy and postpartum in developed countries. However, treatment-based anticoagulants remain controversial ${ }^{1}$.

The primary anticoagulant, warfarin, which crosses the placenta and causes foetal teratogenesis, is contraindicated in pregnancy, except in certain situations. Alternatively, unfractionated heparin (UFH) can be used during this period, although previous literature suggests the use of low molecular weight heparin (LMWH). Both types of heparin do not cross the placental barrier, but LMWH exhibits advantages over UFH with its lower risk of osteopenia, and it does not require constant monitoring of the anticoagulant effect and subsequent dose adjustments. Although bleeding can be a complication of anticoagulant therapy, the use of LMWH during pregnancy has been associated with a reduced incidence of bleeding events and an absence of maternal foetal bleeding. However, clinical and experimental studies have not demonstrated ample evidence of its safety and effects on the development of the embryo-foetus ${ }^{1-3}$.

LMWHs are classified by the Food and Drug Administration (FDA) as a risk category "B" for use during pregnancy and have not been associated with any foetal abnormality or specific incidence of birth defects ${ }^{4,5}$.

Experimental models can be used to assess drug effects on pregnant animals regarding fertility rates and perinatal outcome of their offspring; however, few experimental studies are available that have evaluated the effects of exposure to drugs or procedures on fertility rates in female rats ${ }^{6-9}$.

Due to gaps in the published literature regarding the effects of the anticoagulants, enoxaparin and UFH, in experimental pregnancy models, the objective of this study was to evaluate the effects of exposure to enoxaparin and UFH at prophylactic and therapeutic doses on the fertility of female Wistar rats.

\section{Methods}

This study was approved by the Ethics Committee on Animal Use, Federal University of Mato Grosso do Sul (UFMS) under protocol number 282 of March 11, 2011.

Fifty-five healthy animals of the species Rattus norvegicus Wistar variety were used in this experimental study. Fifty females and five males that initially weighed between 160 and $250 \mathrm{~g}$.

The minimum sample size consisted of eight female rats per group. As presented in the literature, we selected to use ten animals in each group to minimise losses ${ }^{7,8}$. One male was used for every five females, according to the model previously described by Weinstein and Stark ${ }^{10}$.

Male rats were used only for mating purposes. Upon completion of all matings, male rats were sacrificed using decapitation.

The methodology used to determine insemination was performed according to Weinstein and Stark ${ }^{10}$. When sperm was observed in the lamina, which served as an insemination diagnosis, this time point was defined as day "zero" of insemination" ${ }^{11}$. Upon the confirmation of insemination, each rat was randomly divided into one of the experimental groups of this study, at the beginning of the experiment. The animals were housed in cages at a good temperature and humidity and the brightness of its natural cycle on the shelves was controlled in the animal house. Food and water were provided ad libitum before and during the pregnancy.

The enoxaparin and UFH doses were standardised according to human studies previously described in the literature and were adjusted by weight ${ }^{12,13}$. The dilutions were determined for compatibility with the drug administration appropriate for the volume in rats ${ }^{14}$. Thus, the dosages were as follows: enoxaparin (prophylactic dose), $1 \mathrm{mg} / \mathrm{Kg}$, subcutaneously once daily; enoxaparin (therapeutic dose), $2 \mathrm{mg} / \mathrm{kg}$ subcutaneously, in which the dose was divided into two daily doses; heparin (dose prophylactic), $72 \mathrm{UI} / \mathrm{Kg}$, subcutaneously twice a day; and UFH (therapeutic dose), $200 \mathrm{UI} / \mathrm{Kg}$, subcutaneously twice a day.

The pregnant rats were randomly divided into five groups, I to $\mathrm{V}$, which consisted of the control group (I) and experimental groups (II to V). Each group consisted of ten animals. There were no losses during the study.

The groups were broken down according to the anticoagulant used. Thus, the enoxaparin group received a prophylactic dose (Group II) and treatment (Group III), and the UFH group was exposed to prophylactic doses (Group IV) and treatment (Group V).

In the therapeutic dose UFH group (V), the efficacy of anticoagulation was measured by examining the activated partial thromboplastin time (aPTT), in which a value between 1.5 and 2.5 was equivalent to adequate anticoagulation. On the $2 \mathrm{nd}, 7 \mathrm{th}, 14 \mathrm{th}$ and 21 st day of gestation, blood was collected from venous flow in all females for platelet quantification.

The rats were weighed daily for dose adjustment, and exhibited body bruises and bleeding in the gingival, ocular and genital regions as assessed using direct observation, haematochezia/melena or the appearance of stool. The drugs were applied subcutaneously as recommended ${ }^{14}$.

On day 21 of insemination, a surgical procedure of laparotomy was performed on each rat to remove the organs and 
foetuses. Laparotomy was performed with a pre-induction of anaesthesia using midazolam (4 $\mathrm{mg} / \mathrm{kg}$ IM), followed by general anaesthesia using xylazine $(5-10 \mathrm{mg} / \mathrm{kg})$ and ketamine $(50-75 \mathrm{mg} /$ $\mathrm{kg}$ ) intraperitoneally. After surgery, euthanasia was performed with decapitation ${ }^{14,15}$. Foetuses were euthanised by decaptation ${ }^{15}$.

Live foetuses were quantified, the sexes were identified and the placentas were weighed. Also looked for defects in development macroscopic by direct observation as a number of legs, eyes, the presence of tail and training cranial. Next, the uterine horns were dissected, and the presence of early and late reabsorptions was determined by direct observation. The number of implantation sites was determined by the sum of live foetuses, dead foetuses and reabsorptions. The removed ovaries were dissected, and the number of corpus luteum was quantified - which indicated the number of ovulations - (Figures 1 and 2).

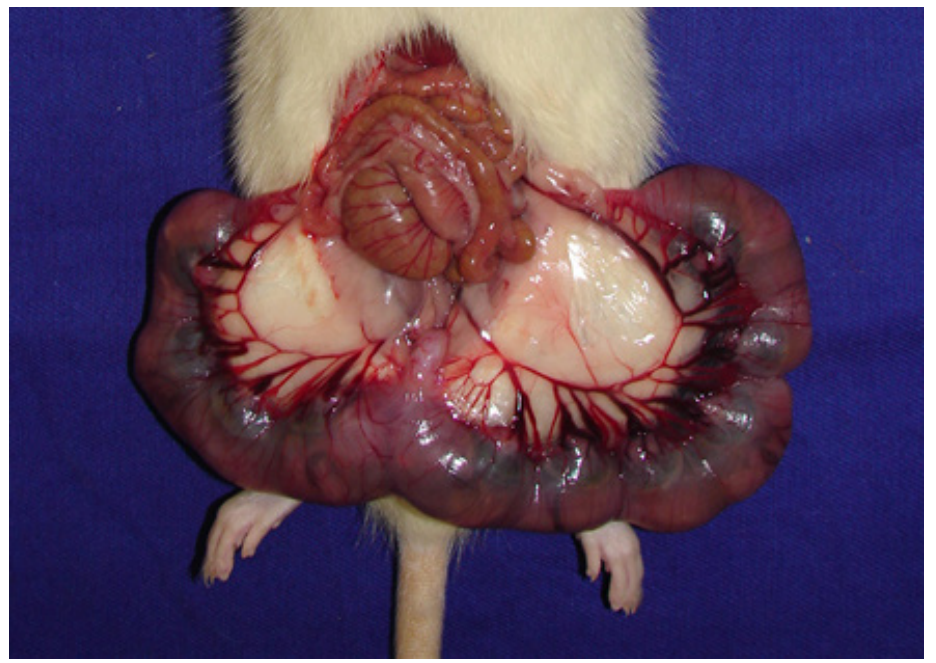

FIGURE 1 - Uterine horns with the presence of fetuses and placentas with 21 days of pregnancy.

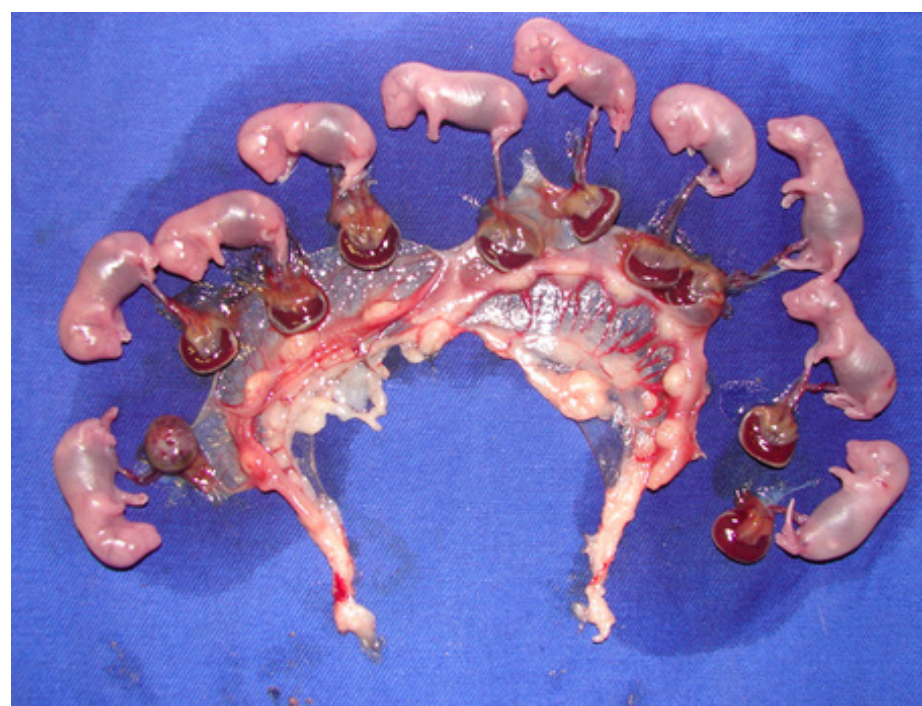

FIGURE 2 - Open uterine horns showing fetuses, placentas, implantation sites and corpora lutea after 21 days of pregnancy.
Using the obtained values, the following calculations were performed to analyse fertility, according to the literature ${ }^{8-10}$ : rate of pre-implantation loss $=$ full corpus luteum - total implantation sites $\times 100 /$ total number of corpus luteum; implantation efficiency rate: total implantation sites $\times 100 /$ Total corpus luteum; rate of post-implantation loss $=$ total implantation sites, total live foetuses $\times 100$ / total implantation sites; and foetal viability rate $=$ total live foetuses $\times 100 /$ total implantation sites.

For statistical analysis of parametric variables with normal distribution and similar variances as the weight of pregnant animals, the number of foetuses, foetal weights and placental tests were used for the Student t-test to compare two groups. To compare three or more groups of the same variables, the ANOVA test was used. To analyse non-parametric variables, such as the fertility rates of the animals, the Mann-Whitney test was used for comparison of two groups. To compare three or more groups with the same variables, the Kruskal-Wallis test was used. To evaluate the frequency of bleeding events, the Fisher exact test was used. P-values $<0.05$ were considered statistically significant. For the calculations, the GraphPad Prism ${ }^{\circledR}$ version 3.00 was used.

\section{Results}

All groups exhibited satisfactory weight gain, and there was no statistically significant differences in the average daily weight gain after seven, 14 and 21 days of pregnancy compared with the control group and compared among groups (Table 1). 
TABLE 1 - Averages of maternal weight gain, daily average foetal weight and mean placental weight after 21 days of pregnancy.

\begin{tabular}{|c|c|c|c|c|c|c|}
\hline Group & $\begin{array}{l}\text { Maternal weight } \\
\text { gain }(\mathrm{g}) \\
\text { Average } \pm \mathbf{1} \text { SD }\end{array}$ & $p^{*}$ & $\begin{array}{c}\text { Foetal weights }(\mathrm{g}) \\
\text { Average } \pm \\
\text { 1 SD }\end{array}$ & $p^{*}$ & $\begin{array}{c}\text { Placental weight }(\mathrm{g}) \\
\text { Average } \pm \\
\text { 1 SD }\end{array}$ & $p^{*}$ \\
\hline I- Control & $8.22 \pm 1.32$ & --- & $5.62 \pm 0.78$ & -- & $0.83 \pm 0.18$ & --- \\
\hline II- Enoxaparin, prophylactic dose & $8.19 \pm 1.08$ & ns & $6.01 \pm 0.24$ & ns & $0.81 \pm 0.15$ & ns \\
\hline III- Enoxaparina, therapeutic dose & $7.92 \pm 1.51$ & ns & $5.83 \pm 0.62$ & $\mathrm{~ns}$ & $0.83 \pm 0.22$ & ns \\
\hline IV- UFH, prophylactic dose & $8.27 \pm 1.25$ & ns & $5.67 \pm 0.55$ & ns & $0.84 \pm 0.17$ & $\mathrm{~ns}$ \\
\hline
\end{tabular}

${ }^{*} p<0.05$ Student t-test (comparison groups vs. control) and ANOVA (comparison among groups). ns - not significant; SD - standard deviation

Analysis of the effects of the anticoagulant employed on perinatal outcome in other characteristics of the litter, such as the weight of the foetuses and placentas (Table 1) and rates of masculinity and femininity, there were no statistical significances between groups versus the control group and when compared among groups.

In addition, there was no statistical significance when the number of foetuses per pregnant animal was compared between groups versus the control group and when compared among groups, as shown in Table 2.

There was no statistical significance between each group and the control group, and the groups were combined to analyse the rates of pre-implantation loss (RPL), rates of efficiency implantation (REI), rates of post-implantation loss (RPIL) and rates of foetal viability (RFV) after 21 days of pregnancy (Table 3 ).

TABLE 2 - Number of foetuses/animals after 21 days of pregnancy.

\begin{tabular}{ccc}
\hline Group & $\begin{array}{c}\text { Number of foetuses/animals } \\
\text { Average } \pm \text { 1 SD }\end{array}$ & $p^{*}$ \\
\hline I- Control & $12.82 \pm 2.34$ & $\mathrm{~ns}$ \\
II- Enoxaparin, prophylactic dose & $11.98 \pm 1.78$ & $\mathrm{~ns}$ \\
III- Enoxaparina, therapeutic dose & $12.23 \pm 1.94$ & $\mathrm{~ns}$ \\
IV- UFH, prophylactic dose & $12.57 \pm 2.03$ & $\mathrm{~ns}$ \\
V- UFH, therapeutic dose & $12.34 \pm 1.56$ & \\
\hline
\end{tabular}

${ }^{*} p<0.05$ Student t-test (comparison groups vs. control) and ANOVA (comparison among groups). ns - not significant; SD - standard deviation

TABLE 3 - Rates of pre-implantation loss, rates of efficiency implantation, rates of post-implantation loss and rates of foetal viability.

\begin{tabular}{|c|c|c|c|c|c|c|c|c|}
\hline Group & $\begin{array}{c}\text { \% RPL } \\
(\text { M P25-P75) }\end{array}$ & $\mathbf{p}^{*}$ & $\begin{array}{c}\text { \%REI } \\
(\text { M P25-P75) }\end{array}$ & $p^{*}$ & $\begin{array}{c}\text { \% RPIL } \\
\text { (M P25-P75) }\end{array}$ & $\mathbf{p}^{*}$ & $\begin{array}{c}\text { \% RFV } \\
\text { (M P25-P75) }\end{array}$ & $\mathbf{p}^{*}$ \\
\hline I- Control & $\begin{array}{c}11.70 \\
(7.80-15.60)\end{array}$ & --- & $\begin{array}{c}88.70 \\
(80.70-93.60)\end{array}$ & --- & $\begin{array}{c}7.20 \\
(6.30-18.7)\end{array}$ & --- & $\begin{array}{c}91.60 \\
(83.70-93.60)\end{array}$ & --- \\
\hline $\begin{array}{l}\text { II- Enoxaparin, prophylactic } \\
\text { dose }\end{array}$ & $\begin{array}{c}12,25 \\
(10.40-14.50)\end{array}$ & ns & $\begin{array}{c}85.60 \\
(81.50-94.80)\end{array}$ & ns & $\begin{array}{c}7.10 \\
(6.30-11.50)\end{array}$ & ns & $\begin{array}{c}92.30 \\
(88.50-94.70)\end{array}$ & ns \\
\hline $\begin{array}{l}\text { III- Enoxaparina, therapeutic } \\
\text { dose }\end{array}$ & $\begin{array}{c}12.10 \\
(9.50-13.80)\end{array}$ & ns & $\begin{array}{c}86.20 \\
(84.20-91.40)\end{array}$ & ns & $\begin{array}{c}8.40 \\
(5.40-22.70)\end{array}$ & ns & $\begin{array}{c}89.70 \\
(78.90-94.80)\end{array}$ & ns \\
\hline IV- UFH, prophylactic dose & $\begin{array}{c}11.80 \\
(7.30-16.40)\end{array}$ & ns & $\begin{array}{c}89.80 \\
(83.60-93.30)\end{array}$ & ns & $\begin{array}{c}7.70 \\
(6.70-14.10)\end{array}$ & ns & $\begin{array}{c}88.60 \\
(83.90-92.40)\end{array}$ & ns \\
\hline V- UFH, therapeutic dose & $\begin{array}{c}11.60 \\
(7.90-14.30)\end{array}$ & ns & $\begin{array}{c}88.40 \\
(84.50-92.30)\end{array}$ & ns & $\begin{array}{c}8.12 \\
(6.50-15.8)\end{array}$ & ns & $\begin{array}{c}88.20 \\
(81.40-93.70)\end{array}$ & ns \\
\hline
\end{tabular}

${ }^{*} p<0.05$ Mann-Whitney (comparison groups vs. control) and Kruskal-Wallis (comparison among groups). ns - not significant; RPL - Rates of pre-implantation loss; REI - rates of efficiency implantation; RPIL - rates of post-implantation loss; RFV - rates of foetal viability 
Regarding the frequency of bleeding events, there was a significantly higher prevalence in the groups exposed to therapeutic doses of anticoagulant drugs (Groups III and V) compared to the control group (Table 4). All bleeding events occurred between 18 to 21 days of gestation. The studies where then temporarily suspended and the drugs doses were recalculated when administration was re-initiated.

No cases of thrombocytopenia (platelet count $<130.000$ / $\mathrm{mm}^{3}$ peripheral venous blood) in the animals were found at all three time points (sevn, 14 and 21 days) and no cases of defects of development macroscopic.

TABLE 4 - Frequency of bleeding events up to day 21 of pregnancy.

\begin{tabular}{ccc}
\hline Groups & Bleeding events \% (x/n) & $\boldsymbol{p}^{*}$ \\
\hline $\begin{array}{c}\text { I- Control } \\
\text { II- Enoxaparin, } \\
\text { prophylactic dose } \\
\begin{array}{c}\text { III- Enoxaparina, } \\
\text { therapeutic dose } \\
\text { IV- UFH, }\end{array}\end{array}$ & $00.00 \%(0 / 10)$ & --- \\
prophylactic dose & $30.00 \%(3 / 10)$ & 0.046 \\
V- UFH, therapeutic dose & $00.00 \%(0 / 10)$ & $\mathrm{ns}$ \\
\hline
\end{tabular}

$* \mathrm{p}<0.05$ Fisher's exact test. ns - not significant

\section{Discussion}

The use of anticoagulants in pregnancy occurs more frequently, particularly with females with thrombophilia, due to improved pregnancy outcomes, as observed in a prospective study of 84 pregnant women using thrombophilia markers. According to this previous study, the use of these drugs resulted in a lower, but statistically significant, rate of abortions, foetal loss, preeclampsia, eclampsia and preterm delivery compared to previous pregnancies of the same patient in the absence of enoxaparin treatment ${ }^{16}$.

UFH exhibits anti-thrombin activity and enoxaparin inhibits activated factor $\mathrm{X}$ in the coagulation signalling cascade. However, both drugs do not cross the placental barrier and thus are preferentially used during pregnancy ${ }^{1}$. However, there is still controversy regarding their use because there are no large clinical trials of anticoagulation in pregnancy and experimental studies are scarce ${ }^{17,18}$. In addition, we performed a literature search on both prophylactic and therapeutic drug dosages and its relationship with fertility rates in rats and found that these studies have been limited.
Most studies on drug exposure and its effects on the fertility of female rats showed an effect on loss rates and pre- or post-deployment, which was increased compared to the control groups $^{8,9}$. However, changes in the loss/gain weight during the use of anticoagulants is not common in gastrointestinal disorders, which reduce the eating habits of rats and explains the lack of differences in loss/gain in weight. These findings were in contrast to previous studies that evaluated the use of anti-retroviral medications $^{8}$ and in cases of stress situations ${ }^{9}$.

Heparin-induced thrombocytopenia is caused by the immune response ${ }^{19}$. Previous studies have described this as a rare event in obstetric patients exposed to UFH or $\mathrm{LMWH}^{20}$. In the present study, although it was not measured in the same frequency as human gestation (which is evaluated at the beginning and end of each equivalent "trimester" of human gestation), we found no case of thrombocytopenia in the examined groups. There was no significant difference between the mean platelet count among groups and compared to the control group.

Experimental studies performed by Erden ${ }^{21}$ and Curcelli ${ }^{12}$ in rats exposed to heparin did not report bleeding. A systematic review comparing LMWH and UFH initially showed fewer bleeding episodes ${ }^{22}$. In this study, the group exposed to enoxaparin at therapeutic doses developed a greater number of bleeding events compared to the group exposed to UFH (Group V), which suggests an inappropriate dose adjustment compared to the weight of the animals.

The drugs used in the present study may interfere with the biochemical processes of implementation and positive embryonic maintenance. Several studies on the effects of heparin on trophoblast invasion and modulation mechanisms and antiapoptotic decidual and placental tissues have shown benefits with the use of these medications ${ }^{21,23}$, which are consistent with the results of this study, in which no differences in fertility rates in Wistar rats exposed to enoxaparin and UFH in prophylactic or therapeutic doses were observed.

UFH and enoxaparin do not cross the placental barrier ${ }^{24}$ and did not demonstrate teratogenic effects in animal studies ${ }^{25}$. Thus, it was expected that no differences occurred in the weight gain of the foetus. Thus, by not interfering with fertility rates of Wistar rats, the use of enoxaparin and UFH in prophylactic and therapeutic doses during the pregnancy of these animals was used.

Despite an extensive literature search, no studies were identified that addressed the scientific experimental fertility rate in the use of heparins during pregnancy, which is consistent with this pioneering study. Thus, further studies using animal models are necessary to assess the potential effects of drug exposure on fertility, 
particularly because studies examining human reproduction are limited, and due to cost, space, time and ethical considerations.

\section{Conclusion}

The effects of exposure of pregnant Wistar rats to the anticoagulant drugs, enoxaparin and unfractionated heparin, in both prophylactic and therapeutic doses, demonstrated that in relationship to pregnancy, no significant changes in fertility rates and prognosis of offspring were observed.

\section{References}

1. Bates SM, Greer IA, Middeldorp S, Veenstra DL, Prabulus AM, Vandvik PO. Venous thromboembolism, thrombophilia, antithrombotic therapy, and pregnancy. American College of Chest Physicians Evidence-Based clinical pratice guidelines (8th edition). Chest. 2012 Feb;14(2)(Supl):e691S-e736S. doi: 10.1378/ chest.11-2300. PubMed PMID:18574280.

2. Empson M, Lassere M, Craig J, Scott J. Prevention of recurrent miscarriage for women with antiphospholipid antibody or lupus anticoagulant. Cochrane Database Syst Rev. 2005 Apr;18(2):CD002859. PubMed PMID: 15846641.

3. Brenner B, Hoffman R, Carp H, Dulitsky M, Younis J, LIVE-ENOX Investigators. Efficacy and safety of two doses of enoxaparin in women with thrombophilia and recurrent pregnancy loss: the LIVEENOX study. J Thromb Haemost 2005 Feb;3:227-9. PubMed PMID: 15670024.

4. Shaikh AK, Kulkarni DM. Drugs in pregnancy and lactation. Int J Basic Clin Pharmacol. 2013 Apr;2(2):130-5. doi:10.5455/23192003.ijbcp20130304.

5. Duhl AJ, Paidas MJ, Ural SH, Branch W, Casele H, Cox-Gill J, Hamersley SL, Hyers TM, Katz V, Kuhlmann R, Nutescu EA, Thorp JA, Zehnder JL; Pregnancy and Thrombosis Working Group. Antithrombotic therapy and pregnancy: consensus report and recommendations for prevention and treatment of venous thromboembolism and adverse pregnancy outcomes. Am J Obst Gynecol. 2007 Nov;197(5):457.e1-457.e21. PubMed PMID: 17980177.

6. Hollembach CB, Bortolini CE, Batiosta JM, Hollembach EB, Schuch TL, Pacheco M. Neonatal development and teratogenic potential of Wistar rats offspring in the study of reproductive toxicity of two commercial phytotherapic preparations with soy Glycine max (L.) Merr. Arq Bras Med Vet Zootec. 2010 Aug;62(4):845-52. doi: 10.1590/ S0102-09352010000400013.

7. Castro AP, Mello FB, Mello JR. Toxicological evaluation of Ginkgo biloba in Wistar rat fertility and reproduction. Acta Sci Vet. 2005;33(3):265-9.

8. Figueiró-filho EA, Duarte G, Rosa e Silva AAM, Fonseca BAL, Mussi-Pinhata MM, Quintana SM. Effects of antiretroviral drugs on fertility of Wistar rats. Rev Bras Ginecol Obstet. 2002 NovDec;24(10):647-52.doi: 10.1590/S0100-7203200200100000.

9. Almeida SA, Kempinas WG, Carvalho TL. Sexual behavior and fertility of male rats submitted to prolonged immobilization-induced stress. Braz J Med Biol Res. 2000 Sep;33:1105-9. PubMed PMID: 10973146

10. Weinstein M, Stark M. Behavioral and biological determinants of fecundability. Ann N Y Acad Sci. 1994 Feb 18;709(18):128-44. PubMed PMID: 8154697.
11. Kato H, Morishige WK, Rothchild I. A quantitative relation between the experimentally determined number of conceptuses and corpus luteum activity in the pregnant rat. Endocrinology. 1979 Sep;105(3):846-50. PubMed PMID: 467342.

12. Curcelli E, Muller SS, Ueda AK, Padovani CR, Maffei FHA, Hossne WS. Effect of heparin-sodium and enoxaparin on rats tibial fracture healing: clinical, anatomopathological, and biomechanical approach. Acta Ortop Bras. 2005;13(1):13-6. doi: 10.1590/S141378522005000100003.

13. Shaughnessy S, Hirsh J, Bhandari M, Muir JM, Young E Weitz JI. A. A histomorphometric evaluation of heparin-induced bone loss after discontinuation of heparin treatment in rats. Blood. $1999 \mathrm{Feb}$ 15;93:1231-6. PubMed PMID: 9949165.

14. Fundação Oswaldo Cruz. Curso de manipulação de animais de laboratório. Rio de Janeiro; 2005. Disponível em http://www. cpqgm.fiocruz.br/arquivos/bioterio/bioterio_apostilha.pdf

15. Fundação Oswaldo Cruz. Manual de utilização de animais/ FIOCRUZ. Rio de Janeiro; 2008. Disponível em http://www. castelo.fiocruz.br/vpplr/comissoes_camaras-tecnicas/Manual_ procedimentos.pdf

16. Figueiró-Filho EA, Oliveira VM, Breda I, Coelho LR, Ferreira CM. Usefulness of a scoring system on perinatal outcomes in pregnant women with thrombophilia in the effectiveness of an enoxaparinbased intervention. Rev Bras Ginecol Obstet. 2012 Oct;34(10):45965. doi: 10.1590/S0100-72032012001000005. PubMed PMID: 23288223

17. Sucak A, Acar K, Celen S, Danisman N, Sucak GT. Outcome of pregnancies in women with thrombophilic disorders. J Obstet Gynaecol. 2010;30(8):847-51.doi: 10.3109/01443615.2010.518649. doi: 10.3109/01443615.2010.518649. PubMed PMID: 21126128.

18. James AH. Pregnancy and thrombotic risk. Crit Care Med. 2010 Feb;38(2 Suppl):S57-63. doi: 10.1097/CCM.0b013e3181c9e2bb. PubMed PMID: 20083915.

19. Junqueira DRG, Carvalho MG, Perini E. Heparin-induced thrombocytopenia: a review of concepts regarding a dangerous adverse drug reaction. Rev Assoc Med Bras. 2013 MarApr;59(2):161-6. doi: 10.1016/j.ramb.2012.11.004. PubMed PMID: 23582558.

20. Warkentin TE, Greinacher A, Koster A, Lincoff AM. Treatment and prevention of heparin-induced thrombocytopenia: American College of Chest Physicians evidence-based clinical practice guidelines (8th Edition). Chest. 2008 Jun;133(6 Suppl):340S-80S. doi: 10.1378/chest.08-0677. doi: 10.1378/chest.08-0677. PubMed PMID: 18574270.

21. Erden O, Imir A, Guvenal T, Muslehiddinoglu A, Arici S, Celtin M. Investigation of the effects of heparin and low molecular weight heparin on E-cadherin and laminin expression in rat pregnancy by immunohistochemistry. Hum Reprod. 2006 Nov;21(11):3014-8. PubMed PMID: 16997938.

22. Erkens PM, Prins MH. Fixed dose subcutaneous low molecular weight heparins versus adjusted dose unfractionated heparin for venous thromboembolism. Cochrane Database Syst Rev. 2010 Sep;8(9):CD001100. doi: 10.1002/14651858.CD001100.pub3. PubMed PMID: 20824828.

23. Zhang Y, Zhong M, Liu F. Low molecular weight heparin inhibits cell apoptosis in the placenta of rats with preeclampsia-like symptoms. Nan Fanq Yi Ke Da Xue Xue Bao. 2012 Jun;32(6):862-6. PubMed PMID: 22699071.

24. Avila WS, Grinberg M. Anticoagulation, pregnancy and cardiopathy. A triad, three dominions and five moments. Arq Bras Cardiol. 2005 Jan;84(1):44-8. PubMed PMID: 15841845.

25. Sanofi-Aventis. Lovenox. Available from http://www.drugs.com/ pro/lovenox.html. 
Figueiró-Filho EA et al.

\section{Acknowledgements}

The technicians of Animal Colony and Bruno Areco Souza, Scientific Initiation Student, UFMS.

\section{Correspondence:}

Ernesto Antonio Figueiró-Filho

Faculdade de Medicina

Universidade Federal do Mato Grosso do Sul

Caixa Postal 549, Cidade Universitária

79070-900 Campo Grande-MS Brasil

Tel.: (55 67)3345-7355

eafigueiro@gmail.com

Received: Feb 17, 2014

Review: April 17, 2014

Accepted: May 22, 2014

Conflict of interest: none

Financial source: none

${ }^{1}$ Research performed at Laboratory of Experimental Surgical Technique, Central, Federal University of Mato Grosso do Sul (UFMS), Campo Grande-MS. Brazil. Part of Master degree thesis, Postgraduate Program in Health and Devolopment of Midwestern Region, FAMED/UFMS. Tutor: Ernesto Antonio Figueiró-Filho. 